\title{
symposium: teaching political science with film
}

In the following collection of articles, Barbara Allen, Ernest Giglio, Richard Ostrom, and Jeffrey Sadow, members of the Conference on Politics \& Film within the American Political Science Association, explore the various aspects of using film and other audio-visual materials in the classroom. Allen discusses how 'priming' and 'framing' techniques in audio-visual media shape viewers' interpretations of social and political issues. Using film in the classroom thus becomes an exercise in teaching students to view mass media representations with a more critical eye. Giglio discusses the advantages and disadvantages of using film as a teaching medium, and suggests a number of films suitable for politics courses. Ostrom lays out a detailed example of how to teach concrete political concepts through the film Battle of Algiers, and proposes how students can use Internet resources to flesh out fictionalised accounts. Finally, Sadow provides some notes on how the Internet can be used as a platform for delivering film and other audio-visual materials.

\section{insights from film}

\section{into political violence and oppression}

\section{barbara allen}

A s a narrative text, film provides an important instructional tool, helping us gain insight into political authority and violence. Race, gender, and class conflict often provide the content of film examinations of dominance and violence. Frequently, however, the message of popular media conveyed in sexual and racial metaphor dims the viewer's awareness of domination, distances the viewer from political debates and deci- sions, and depresses the viewer's sense of political efficacy. Film, and other visual media employing film technique (including, in the United States, news programming), frame reality and prime emotional responses to information with which citizens make political decisions. Even films that attempt to dislodge complacent perceptions of authority and power may find their messages are muted (or even made complicit) with the pervasive cultures of racial and sexual terror and political violence (including the violence of the state) that surround their viewers. By learning to 'read' film texts, students can break through the media framing and priming that encapsulate political information and socialise citizens to accept political domination. 